\title{
A UK-Based Cost-Utility Analysis of Indacaterol, A Once-Daily Maintenance Bronchodilator for Patients with COPD, Using Real World Evidence on Resource Use
}

\author{
David Price • Yumi Asukai · Jaithri Ananthapavan • \\ Bill Malcolm • Amr Radwan · Ian Keyzor
}

Published online: 26 March 2013

(c) The Author(s) 2013. This article is published with open access at Springerlink.com

\begin{abstract}
Introduction Chronic Obstructive Pulmonary Disease (COPD) is a chronic, progressive disease that is not curable. However, there are effective treatments available. In the UK, long-acting bronchodilators are first-line treatments for COPD patients requiring maintenance therapy, and there are several options available. The aim of this study is to establish, from the UK National Health Service (NHS) perspective, the cost-effectiveness profile of indacaterol, the first once-daily long-acting beta 2 -agonist (LABA), compared with tiotropium and salmeterol, in patients with moderate to severe COPD. In assessing the cost-effectiveness of COPD therapies, this study has the advantage of using real world evidence on the resource use associated with COPD management across the spectrum of the disease.
\end{abstract}

Methods A Markov model was developed with four health states following the GOLD classification for severity

\section{Price}

Centre of Academic Primary Care,

University of Aberdeen, Aberdeen, UK

Y. Asukai · J. Ananthapavan ( $\square)$

IMS Health, 210 Pentonville Road, London N1 9JY, UK

e-mail: jananthapavan@uk.imshealth.com

B. Malcolm · A. Radwan · I. Keyzor

Novartis Pharmaceuticals UK Limited, Surrey, UK of airflow limitation. The model time horizon was 3 years, and the cycle length was 3 months. From each state, patients could experience a severe or non-severe exacerbation, move to a different COPD state, remain in the current state or die. Transition probabilities were based on data from the indacaterol clinical trials. The majority of the resource use data was taken from the Optimum Patient Care Research Database (OPCRD), which contains data from over 20,000 COPD patients in England and Scotland. Cost data were taken from UK-based sources and published literature and presented for the cost year 2011. Healthrelated quality of life was the main outcome of interest and utility data for the COPD states were based on data from the indacaterol clinical trials and disutility due to exacerbations were taken from the literature. Both one way and probabilistic sensitivity analyses were performed to test the robustness of the results.

Results Indacaterol dominated in the comparison with salmeterol producing an incremental QALY gain of 0.008 and cost savings of $£ 110$ per patient over a 3 -year time horizon. In the comparison with tiotropium over the same time horizon, indacaterol remained the dominant strategy, producing an incremental QALY gain of 0.008 and cost savings of $£ 248$ per patient. The one-way sensitivity analysis indicates that the proportion of patients in each of the COPD stages and the mortality rate associated with Very Severe COPD are the variables with the largest impact on the results. The probabilistic sensitivity analyses showed that over $72 \%$ and $89 \%$ of the iterations when compared with salmeterol and tiotropium, respectively, produced dominant results for indacaterol.

Conclusion The analyses demonstrate that indacaterol dominates both tiotropium and salmeterol in the base case and is likely to remain cost-effective under a range of assumptions. 


\section{Key Points for Decision Makers}

- Indacaterol is the first once-daily long-acting beta ${ }_{2}$ agonist (LABA) that has been shown to improve lung-function, COPD symptoms, and health-related quality of life (HRQoL) compared to salmeterol and tiotropium.

- The model showed that indacaterol produced cost savings and incremental health benefits over a range of time frames and is therefore a cost-effective alternative to current standard of care for the maintenance treatment of moderate and severe patients with COPD.

- Uncertainty analysis showed that if decision makers are willing to pay $£ 20,000$ per QALY gained, there is over $80 \%$ probability that indacaterol is cost-effective compared to salmeterol and tiotropium.

\section{Introduction}

Chronic obstructive pulmonary disease (COPD) is a progressive, chronic lung disease that is characterised by airflow limitation. The primary symptoms of breathlessness, excessive sputum production, chronic cough and poor exercise tolerance, result in chronic morbidity and mortality [1]. Worldwide, by 2020, COPD is projected to rank fifth in burden of disease [1]. In the UK it is estimated that 3 million people have the disease [2].

In addition to the health impact, COPD also poses a great financial burden. The direct cost of COPD to the UK healthcare system is estimated to be £810-930 million each year and the broader impact on employers and the UK economy is estimated to be $£ 3.8$ billion [3]. Although the direct costs of COPD in the UK can be estimated, there is little published evidence of the real life healthcare consumption of patients in the different stages of COPD.

COPD is not curable; however there are several effective treatments available. The National Institute for Health and Clinical Excellence (NICE) have published treatment algorithms for the adequate management of patients with COPD in the UK [2]. The stepwise progression of inhalation therapies recommended by NICE is based on the best available clinical and cost-effectiveness evidence and aims to improve the standard of care for patients with COPD in the UK [2]. NICE guidelines recommend that patients with moderate to severe COPD initiate maintenance therapy with a long-acting bronchodilator if short-acting bronchodilators are not providing sufficient symptom relief. However there are several long-acting bronchodilators available in the UK. Therefore, healthcare decision makers need to understand which of the available therapies is the most cost-effective from the NHS perspective. Indacaterol is a relatively new once-daily long-acting beta ${ }_{2}$-agonist (LABA) that has been shown to improve lung function, COPD symptoms, and health-related quality of life (HRQoL) endpoints compared with existing monotherapy bronchodilators [4-6].

The use of real-world evidence on the resource use of patients with COPD is valuable in accurately assessing the cost-effectiveness of COPD treatments. The Optimum Patient Care Research Database (OPCRD) [7] contains anonymised research-quality data from patients attending approximately 300 primary care practices in England and Scotland that subscribe to OPCRD for chronic respiratory review services. These data include longitudinal routine clinical data extracted from practice records of over 20,000 patients with a confirmed diagnosis of COPD.

In this analysis, the effectiveness data from two 6-month clinical trials of indacaterol $[4,5]$ (indacaterol 150 and $300 \mu \mathrm{g}$ doses) have been combined with data from the OPCRD [7] on healthcare consumption of COPD patients in the different stages of the disease. The clinical effectiveness and resource use data has been applied within an economic model to estimate the longer term expected costs and outcomes associated with indacaterol's use, compared with tiotropium and salmeterol.

\subsection{Objective}

The aim of this analysis is to use real world evidence of resource use within an economic model to establish the cost-effectiveness profile of indacaterol, the most recent LABA to be launched in the UK, compared with the existing once-daily long-acting muscarinic antagonist (LAMA) tiotropium and the twice-daily LABA salmeterol, in patients with moderate to severe COPD. The analysis took the healthcare payer perspective.

\section{Methods}

\subsection{Model Structure}

COPD is a chronic degenerative disease with recurring exacerbations. A Markov model provides a suitable structure to model such a disease. A Markov model comprises discrete health states that describe the status of a patient. Patients stay in one health state for the duration of a model cycle, accumulating the costs and benefits associated with that health state. At the end of a cycle, patients may remain in a state or move to another state, according to defined transition probabilities.

The model was developed as a global model allowing local country adaptations to inform the cost-effectiveness of indacaterol compared with current treatments. A 
previous publication on the cost-effectiveness of indacaterol in the German setting presents in detail the methodology used to develop the model [8]. This paper presents the specific methods and results for the UK setting.

This analysis used a Markov model constructed in Microsoft Excel 2007 (Microsoft, Redmond, Washington) with four main health states describing the different COPD severities plus a state for death. For each disease severity state, two further health states were created for patients who experienced a severe (requiring hospitalisation) or non-severe exacerbation (requiring medical management in the community), to give a total of 12 health states plus death, as shown in Fig. 1. Mirror states were created for the 12 health states to describe the disease progression of patients who discontinued therapy.

\subsection{Model Parameters}

Cycle lengths were set to 3 months in order to capture initial lung function improvement. Forced Expiratory Volume in 1 second $\left(\mathrm{FEV}_{1}\right)$ was the primary endpoint of the indacaterol studies and most clinical studies show that improvement in trough $\mathrm{FEV}_{1}$ is recorded over the first 8-16 weeks of treatment. Trough $\mathrm{FEV}_{1}$ versus placebo after 12 weeks of treatment was the primary outcome of the indacaterol studies.

Discounting was set to $3.5 \%$ per annum for both costs and outcomes in line with the NICE guidelines for health technology assessments [9]. The time horizon in an economic evaluation should cover the full period over which the benefits and costs of an intervention are expected to be accumulated [9]. Although a lifetime time horizon is recommended in the UK [9]; in the base case, the analysis was run over a 3-year period. The rationale for conducting the analysis over a shorter period was that the relevant clinical trials for indacaterol extended to 6 months and although it is reasonable to expect patients to take indacaterol for longer time periods given that COPD is a life-long, progressive illness; extrapolation of 6-month data to very long time periods would lead to unacceptable levels of uncertainty in the analysis. Several published economic evaluations in COPD have also used shorter than lifetime time horizons [10-13]. A 3-year duration was considered sufficient to capture costs and benefits, given that many patients are likely to step up or discontinue their maintenance therapy after 3 years [14]. The results for a 5-year and lifetime time horizon are also presented.

The model population was based on the patients enrolled in the clinical trials who had moderate to severe COPD (classified by post-bronchodilator $\mathrm{FEV}_{1}$ between $30 \%$ and $80 \%$ of the normal population), a mean age of 63.6 years, and $67 \%$ were male. The starting distribution in the model reflected the baseline distribution of each trial between health states and is presented in Table 1.

COPD guidelines recommend post-bronchodilator measurement of $\mathrm{FEV}_{1}$ for assessment of disease severity [1], but apart from the screening visit, these were not available from the indacaterol trials. As a consequence, and in line with previous economic analyses [11, 15], prebronchodilator values were used to describe efficacy, utilities and medical resource use for the disease severity health states. The available literature all followed the
Fig. 1 Model schematic. Reprinted from Respiratory Medicine, Vol 105, David Price, Alastair Gray, Rupert Gale, Yumi Asukai, Laura Mungapen, Adam Lloyd, Lars Peters, Katja Neidhardt, Tobias Gantner, Cost-utility analysis of indacaterol in Germany: a oncedaily maintenance bronchodilator for patients with COPD, pp 1635-1647, Copyright (2011), with permission from Elsevier

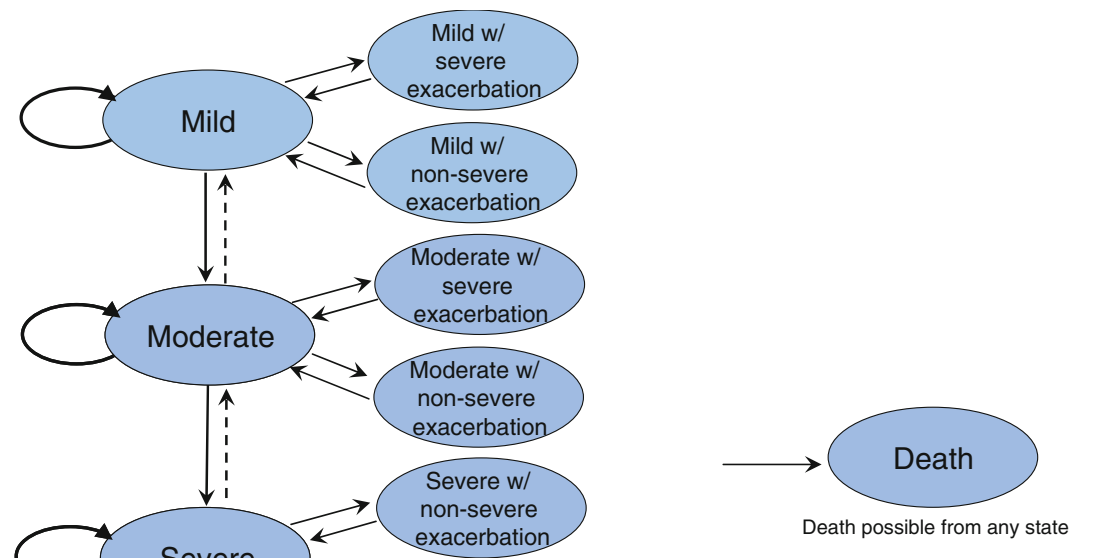

$\triangle$ Adis 
Table 1 Patient characteristics [8]

\begin{tabular}{lcc}
\hline Trial & INHANCE & INLIGHT-2 \\
\hline Study arms & $\begin{array}{c}\text { Indacaterol } \\
150 \mu \mathrm{g}\end{array}$ & $\begin{array}{c}\text { Indacaterol } \\
150 \mu \mathrm{g}\end{array}$ \\
& $\begin{array}{c}\text { Indacaterol } \\
300 \mu \mathrm{g}\end{array}$ & $\begin{array}{c}\text { Salmeterol } \\
2 \times 50 \mu \mathrm{g}\end{array}$ \\
& $\begin{array}{c}\text { Tiotropium } \\
18 \mu \mathrm{g}\end{array}$ & \\
& 26 weeks & 26 weeks \\
& 1683 & 998 \\
Length of study & & \\
Number of subjects & $63.6(9.1)$ & $63.5(8.81)$ \\
$\quad$ (randomised) & & \\
Mean age, years & 62.8 & 74.6 \\
$\quad$ standard deviation) & $6.8(6.75)$ & $6.5(5.71)$ \\
Proportion of males $(\%)$ & & \\
Duration of COPD, years & & \\
$\quad$ standard deviation) & 1.4 & 1.2 \\
Starting disease severity distribution $(\%)$ & 41.3 \\
$\quad$ Mild COPD & 36.7 & 49.4 \\
Moderate COPD & 50.2 & 8.1 \\
Severe COPD & 11.69 & \\
Very Severe COPD & &
\end{tabular}

convention of using pre-bronchodilator values to define these data and since pre-bronchodilator values were used for all comparators the impact on incremental results was minimal. The cut-off points adopted in the clinical trials to define COPD severity were the same as the Global Initiative for Chronic Obstructive Lung Disease (GOLD) [1], which compares patient $\mathrm{FEV}_{1}$ with $\mathrm{FEV}_{1}$ for the normal population to ascertain percentage of normal lung function.

\subsection{Analysis}

A cohort analysis was conducted with the Markov model, based on a population of 1,000 patients. Expected costs and outcomes were used to estimate a total cost, total life-years gained, total severe and non-severe exacerbations and total quality adjusted life-years (QALYs) gained per patient. Incremental cost-effectiveness ratios were reported as cost per QALY gained.

Both one-way and probabilistic sensitivity analyses (PSA) were conducted to test the assumptions of the model and the overall robustness of the results. Tornado diagrams give an indication of the parameters/assumptions which are particularly important contributors to the model's results. Parameters from clinical trial data were varied within the $95 \%$ CIs and parameters for which data on uncertainty were not available were varied by $\pm 30 \%$. For the PSA, costs and resource use were varied according to a gamma distribution, utilities by a beta distribution and rate ratios by a log-normal distribution. These distributions were stochastically sampled for 1,000 iterations and the ICER output was recorded. The results of the PSA are shown on a cost-effectiveness plane, where the incremental costs and incremental QALYs for each iteration of the PSA are plotted. The quadrant in which the ICER falls is informative of the cost-effectiveness of the treatment under evaluation.

A threshold analysis was also conducted to assess the impact of using lower prices for tiotropium on the costeffectiveness results. This is aimed to reflect the situation when branded tiotropium loses exclusivity in the UK.

\subsection{Clinical Model Inputs}

Two key, 6-month trials for indacaterol informed the clinical inputs for the model. The trials were both multicentre, placebo-controlled, randomised studies with active controls $[4,5]$. The INLIGHT-2 trial was a double-blind study comparing indacaterol (Onbrez Breezhaler ${ }^{\circledR}$, Novartis) $150 \mu \mathrm{g}$ daily, salmeterol (Serevent $\left.{ }^{\circledR}, \mathrm{A} \& \mathrm{H}\right) 50 \mu \mathrm{g}$ twice daily and placebo [5]; the INHANCE trial compared indacaterol 150 or $300 \mu \mathrm{g}$ daily with open-label tiotropium (Spiriva $^{\circledR}$, Boehringer Ingelheim) $18 \mu \mathrm{g}$ daily [4]. Each trial provided data on the rate of exacerbations and the improvement in lung function (trough $\mathrm{FEV}_{1}$ at week 12 was the primary endpoint). Detailed patient characteristics for these trials have been previously published [8].

Data from the trials using indacaterol $150 \mu \mathrm{g}$ dose is presented as the base case as this is the most commonly recommended dose licensed in the UK. Patients are allowed to increase their dose to the $300 \mu \mathrm{g}$ dose on medical advice, which has been shown to provide additional clinical benefit for patients with severe COPD and therefore the results of the comparison of indacaterol $300 \mu \mathrm{g}$ versus tiotropium $18 \mu \mathrm{g}$ have also been presented. Indacaterol $300 \mu \mathrm{g}$ was not included in the trial versus salmeterol and therefore there are no efficacy results available to inform this comparison in the model.

\section{5 $\mathrm{FEV}_{1}$ Improvement}

Transition probabilities used in the model were based on transition matrices constructed from individual patient level data, which tracked the movement of patients over the first 12 weeks across different disease states. This allowed the model to fully capture change in disease states rather than using aggregated average improvement in $\mathrm{FEV}_{1}$ levels. As discussed above, the primary endpoint of the indacaterol trials was $\mathrm{FEV}_{1}$ improvement at week 12 which is a commonly used regulatory time frame cut-off for registration clinical studies. The transition matrices describing the movement of patients over the first 12 weeks in the INHANCE and INLIGHT-2 trials are presented in Table 2. This transition matrix was applied to the first cycle (12 weeks) of the model only, to describe the initial 
Table 2 Transition matrix (baseline to 12 weeks) from the INHANCE and INLIGHT-2 trials

\begin{tabular}{|c|c|c|c|c|}
\hline & \multicolumn{4}{|l|}{ From } \\
\hline & Mild & Moderate & Severe & Very Severe \\
\hline \multicolumn{5}{|l|}{ INHANCE } \\
\hline \multicolumn{5}{|c|}{$150 \mu \mathrm{g}$ indacaterol } \\
\hline \multicolumn{5}{|l|}{ To } \\
\hline Mild & $60.00 \%$ & $8.22 \%$ & $0.64 \%$ & $0.00 \%$ \\
\hline Moderate & $40.00 \%$ & $84.25 \%$ & $38.85 \%$ & $2.63 \%$ \\
\hline Severe & $0.00 \%$ & $7.53 \%$ & $58.60 \%$ & $63.16 \%$ \\
\hline Very Severe & $0.00 \%$ & $0.00 \%$ & $1.91 \%$ & $34.21 \%$ \\
\hline \multicolumn{5}{|c|}{$300 \mu \mathrm{g}$ indacaterol } \\
\hline \multicolumn{5}{|c|}{ To } \\
\hline Mild & $62.50 \%$ & $15.07 \%$ & $0.60 \%$ & $0.00 \%$ \\
\hline Moderate & $25.00 \%$ & $78.77 \%$ & $38.32 \%$ & $9.09 \%$ \\
\hline Severe & $12.50 \%$ & $5.48 \%$ & $58.68 \%$ & $63.64 \%$ \\
\hline Very Severe & $0.00 \%$ & $0.68 \%$ & $2.40 \%$ & $27.27 \%$ \\
\hline \multicolumn{5}{|c|}{$18 \mu \mathrm{g}$ tiotropium } \\
\hline \multicolumn{5}{|c|}{ To } \\
\hline Mild & $60.00 \%$ & $11.11 \%$ & $0.52 \%$ & $0.00 \%$ \\
\hline Moderate & $40.00 \%$ & $84.26 \%$ & $30.89 \%$ & $2.33 \%$ \\
\hline Severe & $0.00 \%$ & $4.63 \%$ & $64.40 \%$ & $55.81 \%$ \\
\hline Very Severe & $0.00 \%$ & $0.00 \%$ & $4.19 \%$ & $41.86 \%$ \\
\hline \multicolumn{5}{|l|}{ INLIGHT-2 } \\
\hline \multicolumn{5}{|c|}{$150 \mu \mathrm{g}$ indacaterol } \\
\hline \multicolumn{5}{|c|}{ To } \\
\hline Mild & $66.67 \%$ & $14.29 \%$ & $0.69 \%$ & $0.00 \%$ \\
\hline Moderate & $33.33 \%$ & $75.40 \%$ & $27.59 \%$ & $0.00 \%$ \\
\hline Severe & $0.00 \%$ & $9.52 \%$ & $68.97 \%$ & $57.14 \%$ \\
\hline Very Severe & $0.00 \%$ & $0.79 \%$ & $2.76 \%$ & $42.86 \%$ \\
\hline \multicolumn{5}{|c|}{$2 \times 50 \mu$ g salmeterol } \\
\hline \multicolumn{5}{|c|}{ To } \\
\hline Mild & $75.00 \%$ & $9.57 \%$ & $0.00 \%$ & $0.00 \%$ \\
\hline Moderate & $25.00 \%$ & $80.87 \%$ & $23.08 \%$ & $0.00 \%$ \\
\hline Severe & $0.00 \%$ & $9.57 \%$ & $70.63 \%$ & $53.85 \%$ \\
\hline Very Severe & $0.00 \%$ & $0.00 \%$ & $6.29 \%$ & $46.15 \%$ \\
\hline
\end{tabular}

Reprinted from Respiratory Medicine, Vol 105, David Price, Alastair Gray, Rupert Gale, Yumi Asukai, Laura Mungapen, Adam Lloyd, Lars Peters, Katja Neidhardt, Tobias Gantner, Cost-utility analysis of indacaterol in Germany: a once-daily maintenance bronchodilator for patients with COPD, pp 1635-1647, Copyright (2011), with permission from Elsevier

improvement in $\mathrm{FEV}_{1}$ after starting therapy. After the first cycle, all patients experience a uniform lung function decline over the model duration (Table 3).

\subsection{Exacerbation Rates}

The observed exacerbation rates from the placebo control arms of the indacaterol trials were used in the model.
Annual rates in the placebo arm were similar across the trials ranging from 0.60 to 0.74 exacerbations per patient per year and these rates set the overall number of exacerbations that occurred in the model. The definition of an exacerbation in the model was based on resource use and differs from that of the clinical trial; severe exacerbations were those requiring hospitalisation and non-severe were those requiring a change in medication and/or contact with a healthcare provider. The probability that an exacerbation would be severe or non-severe in each of the severity stages was based on the clinical trial data. Exacerbations from the placebo arm of the indacaterol trials were pooled and the most recent pre-bronchodilator $\mathrm{FEV}_{1}$ value recorded before an exacerbation was used to classify the disease severity status in which the exacerbation took place.

The treatment effect on exacerbation reduction was described as rate ratios and based on the respective studies. Annual rates of exacerbations for the active arms were low in the clinical trials (typically around 0.5 per patient for all treatments) since the study was not enriched to recruit an exacerbating population. All rate ratios were applied to the baseline rate of exacerbations, and therefore rate ratios versus placebo were used. Annual exacerbation rates could not be derived for each treatment by disease severity from the trial data due to the small number of observed events in each study (Table 3).

\subsection{Other Clinical Inputs}

A differential rate of lung function decline was not demonstrated in these two studies and the rate of lung function decline for COPD patients was therefore derived from the UPLIFT [16] trial, which gave the annual rate of decline in pre-bronchodilator $\mathrm{FEV}_{1}$ measurements as $30 \mathrm{ml}$ per year with a standard error of $1 \mathrm{ml}$; the UPLIFT trial is one of the longest COPD trials conducted recently (Table 3 ).

Two different mortality rates were utilised in the model in order to fully describe the death rate of a COPD population. The first was a COPD-related mortality and the second was an all-cause mortality rate used to account for deaths from competing causes in the study population. COPD-related mortality was obtained from a published study which gave mortality rates for a COPD patient cohort grouped by disease severity [12]. While this source accounts for all-cause mortality within this cohort, we have made the assumption that all deaths recorded within this study were COPD-related, since separate measures of COPD-attributable death by disease severity (required to separate the types of death) were not available (Table 3). All-cause mortality was obtained from UK interim life tables for 2008-10 issued by the Office for National Statistics [17]. In the model, all-cause mortality was not adjusted for COPD-specific deaths due to lack of data. 
Table 3 Other model parameters

\begin{tabular}{|c|c|c|c|c|}
\hline Parameter & Value & Range used in SA & Distribution & Source \\
\hline Discount rate $(\%)$ & 3.5 & $\mathrm{NA}^{\mathrm{a}}$ & $\mathrm{NA}^{\mathrm{a}}$ & NICE 2009 [9] \\
\hline Discontinuation rate $(\%)$ & 1.73 & $1.24-4.88$ & Beta & Assumption ${ }^{\mathrm{b}}$ \\
\hline Lung volume decline per year $(\mathrm{ml})$ & 30 & $28-52$ & Normal & Tashkin et al. $2008[16]^{\mathrm{c}}$ \\
\hline $\begin{array}{l}\text { Probability of progression to the next COPD } \\
\text { severity state }\end{array}$ & 0.9 & $\begin{array}{l}\text { Range based on stochastic } \\
\text { sampling of lung volume } \\
\text { decline }\end{array}$ & $\mathrm{NA}^{\mathrm{a}}$ & $\begin{array}{l}\text { Calculated based on } \mathrm{FEV}_{1} \\
\text { decline reported in Tashkin } \\
\text { et al. } 2008 \text { [16] }\end{array}$ \\
\hline $\begin{array}{l}\text { Exacerbation rate ratio versus placebo: } \\
\text { indacaterol } 150 \mu \mathrm{g} \text { (salmeterol analysis) }\end{array}$ & 0.75 & $0.46-1.21^{\mathrm{d}}$ & Lognormal & $\begin{array}{l}\text { INHANCE and INLIGHT-2 } \\
\text { clinical trials }\end{array}$ \\
\hline $\begin{array}{l}\text { Exacerbation rate ratio versus placebo: } \\
\text { salmeterol } 150 \mu \mathrm{g}\end{array}$ & 0.63 & $0.38-1.05^{\mathrm{d}}$ & Log normal & $\begin{array}{l}\text { INHANCE and INLIGHT-2 } \\
\text { clinical trials }\end{array}$ \\
\hline $\begin{array}{l}\text { Exacerbation rate ratio versus placebo: } \\
\text { indacaterol } 150 \mu \mathrm{g} \text { (tiotropium comparison) }\end{array}$ & 0.67 & $0.46-0.99^{\mathrm{d}}$ & Log normal & $\begin{array}{l}\text { INHANCE and INLIGHT-2 } \\
\text { clinical trials }\end{array}$ \\
\hline $\begin{array}{l}\text { Exacerbation rate ratio versus placebo: } \\
\text { indacaterol } 300 \mu \mathrm{g} \text { (tiotropium comparison) }\end{array}$ & 0.75 & $0.51-1.08^{\mathrm{d}}$ & Log normal & $\begin{array}{l}\text { INHANCE and INLIGHT-2 } \\
\text { clinical trials }\end{array}$ \\
\hline $\begin{array}{l}\text { Exacerbation rate ratio versus placebo: } \\
\text { tiotropium } 18 \mu \mathrm{g}\end{array}$ & 0.70 & $0.48-1.03^{\mathrm{d}}$ & Log normal & $\begin{array}{l}\text { INHANCE and INLIGHT-2 } \\
\text { clinical trials }\end{array}$ \\
\hline Probability of death due to Mild COPD & $0^{\mathrm{e}}$ & $0-0^{f}$ & Beta & Rutten-van Molken 2007 [12] \\
\hline Probability of death due to Moderate COPD & $0.003^{\mathrm{e}}$ & $0-009^{\mathrm{f}}$ & Beta & Rutten-van Molken 2007 [12] \\
\hline Probability of death due to Severe COPD & $0.006^{\mathrm{e}}$ & $0-0.018^{\mathrm{f}}$ & Beta & Rutten-van Molken 2007 [12] \\
\hline Probability of death due to Very Severe COPD & $0.024^{\mathrm{e}}$ & $0-0.053^{\mathrm{f}}$ & Beta & Rutten-van Molken 2007 [12] \\
\hline
\end{tabular}

${ }^{\text {a }}$ Variable not included in sensitivity analysis

${ }^{\mathrm{b}}$ Calculated based on an assumption of an annual discontinuation rate of $7 \%$ that varies between $5 \%$ and $20 \%$

c Standard error reported in Tashkin et al. 2008 [16] was used to estimate the range used in the sensitivity analyses

${ }^{\mathrm{d}}$ Sensitivity analyses range based on $95 \%$ confidence interval

e Values from Rutten-van Molken [12] have been adjusted for the 3-month model cycle length

${ }^{\mathrm{f}}$ Sensitivity analyses range based on $95 \%$ confidence interval for the rate of exacerbations from the indacaterol clinical trials $C O P D$ chronic obstructive pulmonary disease, $N A$ not available, $S A$ sensitivity analyses

\subsection{Economic Model Inputs}

Unit costs were obtained from a combination of UK cost sources and costs from the literature. Table 4 shows the unit costs for all healthcare products and services used in the model. All costs are expressed as Pounds Sterling (£) for the cost year 2011 and have been inflated to 2011 prices using the Hospital and Community Health Services Index [18] where necessary. Resource use from the OPCRD [7] and the literature was validated with a UK clinician with expertise in COPD management.

The cost of the different disease states and exacerbations consist of costs accrued in the community and the hospital setting. The cost of community-based care providers were taken from the Personal Social Services Research Unit (PSSRU) [18] and all hospital services including ambulance, admission costs, professional and lab services were taken from the NHS reference costs 2009-2010 [19].

Drug prices were obtained from the British National Formulary (BNF) [20]. For COPD-specific drugs, the recommended dose and package size was used to calculate the cost per day. For the influenza and pneumococcal vaccine, the unit cost to the Department of Health was used, which includes the cost of the vaccine and the GP administration fee [3]. The OPCRD [7] reports the number of prescriptions for a specific drug class over a 12-month period. Therefore for these drugs (short-acting beta-2 agonists (SABA), short-acting antimuscarinic bronchodilator (SAMA), inhaled corticosteroids (ICS), leukotriene receptor antagonists (LTRA), theophylline, mucolytics and oral corticosteroids), the Prescription Cost Analysis dataset 2011 [21] was used to ascertain the average cost per prescription. The weighted average cost per prescription of the five most common products in each of the drug classes was used.

Home oxygen therapy in the UK is supplied by the Home Oxygen Service which uses specific contractors to supply oxygen in patients' homes [22]. The cost of this service was not readily available and therefore the cost per day of oxygen therapy reported in a published cost-effectiveness analysis [11] has been inflated and converted from local currency and used in the model. NICE clinical guidelines recommend that all very severe COPD patients are assessed for home oxygen [2]. It is reported that 
Table 4 Cost for health care products and services used in the model

${ }^{a}$ During exacerbations

$B N F$ British national formulary, $C O P D$ chronic obstructive pulmonary disease, $G P$ general practitioner, ICS inhaled corticosteroids, LTRA

leukotriene receptor antagonist, NHS National Health Service,

$P C A$ prescription cost analysis, PSSRU personal social services research unit, $S A B A$ short-acting beta-2 agonists, SAMA shortacting antimuscarinic bronchodilator

\begin{tabular}{|c|c|c|}
\hline Item & 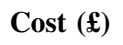 & Source \\
\hline \multicolumn{3}{|l|}{ Health care services } \\
\hline GP visit & 36.00 & PSSRU 2011 [18] \\
\hline Outpatient respiratory specialist visit & 134.61 & NHS Reference Costs 2009-10 [19] \\
\hline Physiotherapist (per hour) & 34.00 & PSSRU 2011 [18] \\
\hline Spirometry & 51.38 & NHS Reference Costs 2009-10 [19] \\
\hline Hospitalisation for COPD exacerbation & 1693.40 & NHS Reference Costs 2009-10 [19] \\
\hline Ambulance transportation to emergency & 239.42 & NHS Reference Costs 2009-10 [19] \\
\hline Pulmonary rehabilitation & 1017.27 & Department of Health 2010 [3] \\
\hline Home oxygen therapy (per day) & 15.33 & Oostenbrink et al. 2005 [11] \\
\hline \multicolumn{3}{|l|}{ Drug } \\
\hline Indacaterol $150 \mu \mathrm{g}$ (daily) & 0.98 & BNF $62[20]$ \\
\hline Indacaterol $300 \mu \mathrm{g}$ (daily) & 0.98 & BNF $62[20]$ \\
\hline Tiotropium $18 \mu \mathrm{g}$ (daily) & 1.06 & BNF $62[20]$ \\
\hline Salmeterol $2 \times 50 \mu \mathrm{g}$ (daily) & 0.98 & BNF $62[20]$ \\
\hline Theophylline (per script) & 3.43 & PCA 2011 [21] \\
\hline Mucolytics (per script) & 21.85 & PCA 2011 [21] \\
\hline Oral corticosteroids (per script) & 8.79 & PCA 2011 [21] \\
\hline SABA (per script) & 5.98 & PCA $2011[21]$ \\
\hline ICS (per script) & 12.12 & PCA $2011[21]$ \\
\hline SAMA (per script) & 10.24 & PCA $2011[21]$ \\
\hline LTRA (per script) & 31.77 & PCA $2011[21]$ \\
\hline Influenza vaccination (per administration) & 14.20 & Department of Health 2010 [3] \\
\hline Pneumococcal vaccination (per administration) & 46.75 & Department of Health 2010 [3] \\
\hline Oral corticosteroids, $30 \mathrm{mg}^{\mathrm{a}}$ (per day) & 0.58 & BNF $62[20]$ \\
\hline Antibiotics $^{\mathrm{a}}$ (per day) & 0.98 & PCA [21]; BNF 62 [20] \\
\hline
\end{tabular}

Resource use associated with exacerbations was approximately $40 \%$ of very severe COPD patients should be on home oxygen, however currently it is believed that only half of those who require home oxygen receive it [3]. In the base case, it is assumed that all patients who require home oxygen receive it (i.e. $40 \%$ of very severe COPD patients [3] and $5 \%$ of severe COPD patients).

There was limited evidence on the cost of delivering pulmonary rehabilitation to COPD patients in the UK. The cost estimate used in the model was taken from a report by the Department of Health on the development of a national strategy for COPD services [3].

This analysis used real-life resource use from the OPCRD [7]. Of the over 28,000 COPD subjects in the database, 20,001 patients had a confirmed diagnosis with an $\mathrm{FEV}_{1} /$ Forced Vital Capacity $(\mathrm{FVC})$ ratio $<0.7$. Using the 20,001 subjects, the average use of concomitant medications (SABA, SAMA, ICS, LTRA, theophylline, mucolytics and oral corticosteroids), pulmonary rehabilitation and GP consultations related to COPD were calculated for each of the COPD GOLD stages. Resource use data not available in the OPCRD [7] (respiratory specialist visits, and spirometry) were taken from the literature [11]. Table 5 shows the resource utilization rates for the health states that were applied in the model. unavailable from the OPCRD [7] and therefore are based on assumptions that have been validated by a clinician. For a non-severe exacerbation, it was assumed that all patients visited the GP once, and $50 \%$ took antibiotics and oral corticosteroids for 7 days and $50 \%$ took these therapies for 14 days (an average of 10.5 days for all patients). For severe exacerbations it was assumed that $70 \%$ of patients arrived at hospital in an ambulance before they were admitted. In addition it was assumed that patients took antibiotics and oral corticosteroids for 10.5 days (Table 6).

\subsection{Utility Inputs}

European Quality of Life - five dimensions (EQ-5D) is a standardised questionnaire used to measure HRQoL and allows the calculation of a utility value for a specific health state [23]. EQ-5D data were collected in the three indacaterol phase III clinical trials at the start of the studies, at week 12 (primary endpoint) and at week 26 (end of the studies) [24]. In the indacaterol trials, whenever an EQ-5D questionnaire was completed at a time for which a prebronchodilator $\mathrm{FEV}_{1}$ value was available, the EQ-5D score was labelled as describing the corresponding disease 
Table 5 Resource utilisation for model health states

\begin{tabular}{|c|c|c|c|c|c|c|c|c|c|c|}
\hline $\begin{array}{l}\text { Annual resource } \\
\text { utilisation for } \\
\text { maintenance }\end{array}$ & Mild & $\begin{array}{l}\text { Range } \\
\text { used in } \mathrm{SA}\end{array}$ & Moderate & $\begin{array}{l}\text { Range used } \\
\text { in SA }\end{array}$ & Severe & $\begin{array}{l}\text { Range used } \\
\text { in SA }\end{array}$ & $\begin{array}{l}\text { Very } \\
\text { Severe }\end{array}$ & $\begin{array}{l}\text { Range used } \\
\text { in SA }\end{array}$ & Distribution & Source \\
\hline $\begin{array}{l}\text { Influenza } \\
\text { vaccination }\end{array}$ & 0.73 & $0.53-0.93^{\mathrm{a}}$ & 0.73 & $0.53-0.93^{\mathrm{a}}$ & 0.73 & $0.53-0.93^{\mathrm{a}}$ & 0.73 & $0.53-0.93^{\mathrm{a}}$ & Beta & $\begin{array}{c}\text { Department of } \\
\text { Health/HPA } \\
2011[32]\end{array}$ \\
\hline $\begin{array}{l}\text { Pneumococcal } \\
\text { vaccination }\end{array}$ & 0.69 & $0.49-0.89^{\mathrm{a}}$ & 0.69 & $0.49-0.89^{\mathrm{a}}$ & 0.69 & $0.49-0.89^{\mathrm{a}}$ & 0.69 & $0.49-0.89^{\mathrm{a}}$ & Beta & $\begin{array}{l}\text { Department of } \\
\text { Health [3] }\end{array}$ \\
\hline $\begin{array}{l}\text { Theophylline } \\
\text { (number of } \\
\text { scripts) }\end{array}$ & 0.26 & $0.18-0.34^{\mathrm{b}}$ & 0.32 & $0.22-0.41^{\mathrm{b}}$ & 0.73 & $0.51-0.95^{\mathrm{b}}$ & 1.63 & $1.14-2.11^{\mathrm{b}}$ & Gamma & OPCRD 2012 [7] \\
\hline $\begin{array}{l}\text { Mucolytics (number } \\
\text { of scripts) }\end{array}$ & 0.35 & $0.24-0.45^{\mathrm{b}}$ & 0.40 & $0.28-0.52^{\mathrm{b}}$ & 0.80 & $0.56-1.05$ & 2.05 & $1.43-2.66$ & Gamma & OPCRD 2012 [7] \\
\hline $\begin{array}{l}\text { Oral corticosteroids } \\
\text { (number of } \\
\text { scripts) }\end{array}$ & 0.88 & $0.61-1.14^{\mathrm{b}}$ & 0.96 & $0.67-1.25^{\mathrm{b}}$ & 1.70 & $1.19-2.21$ & 2.70 & $1.89-3.52^{\mathrm{b}}$ & Gamma & $\begin{array}{r}\text { OPCRD } 2012 \text { [7] } \\
\text { clinical opinion }\end{array}$ \\
\hline $\begin{array}{l}\text { SABA (number of } \\
\text { scripts) }\end{array}$ & 3.74 & $2.62-4.86^{\mathrm{b}}$ & 4.65 & $3.25-6.04^{\mathrm{b}}$ & 6.87 & $4.81-8.93^{b}$ & 9.78 & $6.85-12.71^{\mathrm{b}}$ & Gamma & OPCRD 2012 [7] \\
\hline $\begin{array}{l}\text { ICS (number of } \\
\text { scripts) }\end{array}$ & 0.89 & $0.62-1.16^{\mathrm{b}}$ & 0.81 & $0.57-1.05^{\mathrm{b}}$ & 0.71 & $0.50-0.93^{b}$ & 0.62 & $0.44-0.81^{b}$ & Gamma & OPCRD 2012 [7] \\
\hline $\begin{array}{l}\text { SAMA (number of } \\
\text { scripts) }\end{array}$ & 0.59 & $0.41-0.77^{\mathrm{b}}$ & 0.65 & $0.46-0.85^{\mathrm{b}}$ & 0.91 & $0.64-1.19^{b}$ & 1.19 & $0.84-1.55^{\mathrm{b}}$ & Gamma & OPCRD 2012 [7] \\
\hline $\begin{array}{l}\text { LTRA (number of } \\
\text { scripts) }\end{array}$ & 0.00 & $0^{\mathrm{b}}$ & 0.00 & $0^{\mathrm{b}}$ & 0.37 & $0.26-0.48^{\mathrm{b}}$ & 0.00 & $0^{\mathrm{b}}$ & Gamma & OPCRD 2012 [7] \\
\hline $\begin{array}{l}\text { Pulmonary } \\
\text { rehabilitation }\end{array}$ & 0.02 & $0.02-0.03^{\mathrm{b}}$ & 0.03 & $0.02-0.04^{\mathrm{b}}$ & 0.06 & $0.04-0.08^{b}$ & 0.09 & $0.06-0.12^{b}$ & & OPCRD 2012 [7] \\
\hline $\begin{array}{l}\text { Home oxygen } \\
\text { therapy } \\
\text { (proportion of } \\
\text { patients) }\end{array}$ & 0.00 & $0^{\mathrm{b}}$ & 0.00 & $0^{\mathrm{b}}$ & 0.05 & $0.04-0.07^{\mathrm{b}}$ & 0.40 & $0.28-0.52^{b}$ & Beta & $\begin{array}{l}\text { Clinical opinion; } \\
\text { Department of } \\
\text { Health [3] }\end{array}$ \\
\hline GP visits & 15.05 & $10.54-19.57^{b}$ & 15.76 & $11.03-20.48^{\mathrm{b}}$ & 16.20 & $11.34-21.05^{\mathrm{b}}$ & 16.16 & $11.31-21.01^{\mathrm{b}}$ & Gamma & OPCRD 2012 [7] \\
\hline $\begin{array}{l}\text { Outpatient } \\
\text { respiratory } \\
\text { specialist visit }\end{array}$ & 0 & $0^{\mathrm{b}}$ & 0 & $0^{\mathrm{b}}$ & 2 & $1.40-2.60^{\mathrm{b}}$ & 4 & $2.8-5.2^{\mathrm{b}}$ & Gamma & $\begin{array}{l}\text { Oostenbrink et al. } \\
2005 \text { [11] }\end{array}$ \\
\hline $\begin{array}{l}\text { Spirometry (number } \\
\text { of tests) }\end{array}$ & 1 & $0.7-1.3^{\mathrm{b}}$ & 2 & $1.4-2.6^{\mathrm{b}}$ & 2 & $1.4-2.6^{\mathrm{b}}$ & 4 & $2.8-5.2^{\mathrm{b}}$ & Gamma & $\begin{array}{l}\text { Oostenbrink et al. } \\
2005[11]\end{array}$ \\
\hline
\end{tabular}

Resource utilisation was validated by a UK clinician

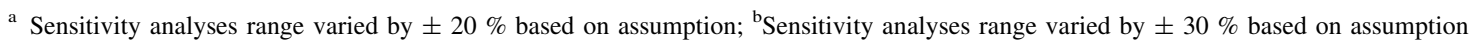

COPD chronic obstructive pulmonary disease, GP general practitioner, HPA health protection agency, ICS inhaled corticosteroids, $L T R A$ leukotriene receptor antagonist, $O P C R D$ optimum patient care research database, $S A$ sensitivity analyses, $S A B A$ short acting beta-2 agonists, $S A M A$ short acting antimuscarinic bronchodilator

severity health state. Over 11,000 EQ-5D questionnaires were pooled and analysed to describe the HRQoL for the COPD disease severity health states. Although the EQ-5D data were collected from subjects across 21 different countries, the UK National Health Survey preference weights was used to value the utility score [24, 25].

No utility data were available from the trials to describe an exacerbation and therefore values from a published study which measured the disutility associated with an exacerbation was used [26]. This study recruited participants from the general population in the Netherlands and aimed to include subjects who represented the Dutch population in terms of age, sex and education level [26]. Participants were asked to value several COPD health profiles using both the visual analogue scale and the time trade-off method [26]. The utility decrements for COPD exacerbations reported using the time trade-off methodology was used in the model (Table 7).

\section{Results}

\subsection{Cost-Utility Analysis}

The deterministic cost-effectiveness results for the comparison of indacaterol $150 \mu \mathrm{g}$ daily to tiotropium $18 \mu \mathrm{g}$ daily and salmeterol $50 \mu \mathrm{g}$ twice daily over a 3-year time horizon are summarized in Table 8. In comparison with salmeterol and tiotropium, indacaterol results in a perpatient cost savings of approximately $£ 110$ and $£ 248$ 
Table 6 Resource utilisation for exacerbations

\begin{tabular}{lllllll}
\hline Resource utilisation per episode & $\begin{array}{l}\text { Non-severe } \\
\text { exacerbation }\end{array}$ & $\begin{array}{l}\text { Range used } \\
\text { in SA }\end{array}$ & $\begin{array}{l}\text { Severe } \\
\text { exacerbation }\end{array}$ & $\begin{array}{l}\text { Range used } \\
\text { in SA }\end{array}$ & Distribution & Source \\
\hline Oral corticosteroids (days of treatment) & 10.50 & $7-14^{\mathrm{a}}$ & 10.50 & $7-14^{\mathrm{a}}$ & Gamma & Clinical opinion \\
Antibiotics (days of treatment) & 10.5 & $7-14^{\mathrm{a}}$ & 10.5 & $7-14^{\mathrm{a}}$ & Gamma & Clinical opinion \\
$\begin{array}{ll}\text { GP visits } \\
\text { Hospitalization }\end{array}$ & 1 & $0.7-1.3^{\mathrm{a}}$ & 0 & 0 & Gamma & Clinical opinion \\
$\begin{array}{l}\text { Ambulance transportation to } \\
\text { emergency (proportion of patients) }\end{array}$ & 0 & 0 & 1 & $\mathrm{NA}^{\mathrm{b}}$ & NA & Assumption \\
\hline
\end{tabular}

${ }^{a}$ Clinical opinion suggests drug taken for between 7-14 days

b Not included in the sensitivity analyses as a hospital admission is part of the definition of a severe exacerbation

${ }^{c}$ Sensitivity analyses range varied by $\pm 30 \%$ based on assumption

GP general practitioner, $N A$ not available, $S A$ sensitivity analyses

Table 7 Utility values

\begin{tabular}{llcll}
\hline & Utility value & Range used in SA & Distribution & Source \\
\hline Stable health state & & & & Pooled indacaterol clinical trials [24] \\
Mild & 0.82 & $0.8-0.84$ & Beta & Pooled indacaterol clinical trials [24] \\
Moderate & 0.80 & $0.79-0.81$ & Beta & Pooled indacaterol clinical trials [24] \\
Severe & 0.77 & $0.77-0.78$ & Beta & Pooled indacaterol clinical trials [24] \\
Very Severe & 0.74 & $0.73-0.76$ & Beta & Source \\
Exacerbations & Utility decrement & & Rutten-van Molken et al. 2009 [26] \\
Non-severe exacerbation & 0.01 & $0-0.024$ & Beta & Rutten-van Molken et al. 2009 [26] \\
Severe exacerbation & 0.042 & $0.024-0.060$ & Beta &
\end{tabular}

$S A$ sensitivity analyses

respectively and produces improved outcomes. This results in indacaterol being in a position of dominance against both comparators.

Table 8 Cost-effectiveness results for indacaterol for a 3-year time horizon

\begin{tabular}{|c|c|c|c|}
\hline & $\begin{array}{c}\text { Indacaterol } \\
150 \mu \mathrm{g}\end{array}$ & $\begin{array}{l}\text { Tiotropium } \\
18 \mu \mathrm{g}\end{array}$ & Difference \\
\hline Total costs & $£ 4534$ & $£ 4781$ & $-£ 248$ \\
\hline \multirow{3}{*}{$\begin{array}{l}\text { Total QALYs } \\
\text { ICER }\end{array}$} & 2.158 & 2.150 & 0.008 \\
\hline & & & Dominant $^{\mathrm{a}}$ \\
\hline & $\begin{array}{c}\text { Indacaterol } \\
150 \mu \mathrm{g}\end{array}$ & $\begin{array}{l}\text { Salmeterol } \\
2 \times 50 \mu \mathrm{g}\end{array}$ & Difference \\
\hline Total costs & $£ 4583$ & $£ 4692$ & $-£ 110$ \\
\hline \multirow{3}{*}{$\begin{array}{l}\text { Total QALYs } \\
\text { ICER }\end{array}$} & 2.158 & 2.149 & 0.008 \\
\hline & & & Dominant $^{\mathrm{a}}$ \\
\hline & $\begin{array}{c}\text { Indacaterol } \\
300 \mu \mathrm{g}\end{array}$ & $\begin{array}{l}\text { Tiotropium } \\
18 \mu \mathrm{g}\end{array}$ & Difference \\
\hline Total costs & $£ 4501$ & $£ 4760$ & $-£ 259$ \\
\hline Total QALYs & 2.162 & 2.151 & 0.011 \\
\hline ICER & & & Dominant $^{\mathrm{a}}$ \\
\hline
\end{tabular}

${ }^{\mathrm{a}}$ Dominant $=$ less cost, better outcomes

ICER incremental cost-effectiveness ratio, $Q A L Y$ quality-adjusted life-years
The INHANCE trial included a comparison of indacaterol $300 \mu \mathrm{g}$ daily against tiotropium $18 \mu \mathrm{g}$ daily. This comparison also results in lower costs and improved benefits for the indacaterol treatment group, also resulting in a position of dominance (Table 8 ). The cost-utility results for the 5-year and lifetime time horizons are presented in Table 9.

\subsection{Other Health Outcomes}

In addition to HRQoL, the model also estimated the amount of exacerbations and mortality over the time horizon. Over the 3-year time horizon, approximately $10 \%$ of patients receiving indacaterol had died compared with $10.8 \%$ of patients receiving salmeterol and $10.4 \%$ receiving tiotropium. Over the same time frame, indacaterol patients experienced 1.21 non-severe exacerbations and 0.09 severe exacerbations. In comparison, the salmeterol and tiotropium patients experienced 1.14 and 1.30 non-severe exacerbations respectively and 0.09 severe exacerbations.

\subsection{Sensitivity Analyses}

The results of one-way sensitivity analyses for indacaterol versus salmeterol and tiotropium are summarised in a 
Table 9 Cost-effectiveness results for indacaterol using a 5 -year and lifetime time horizon

a Dominant $=$ less cost, better outcomes

ICER incremental costeffectiveness ratio, $Q A L Y$ quality-adjusted life-years

\begin{tabular}{|c|c|c|c|}
\hline \multicolumn{4}{|c|}{ 5-year time horizon } \\
\hline & Indacaterol $150 \mu \mathrm{g}$ & Tiotropium $18 \mu \mathrm{g}$ & Difference \\
\hline Total costs & $£ 7102$ & $£ 7457$ & $-£ 355$ \\
\hline Total QALYs & 3.357 & 3.340 & 0.016 \\
\hline \multirow[t]{2}{*}{ ICER } & & & Dominant $^{\mathrm{a}}$ \\
\hline & Indacaterol $150 \mu \mathrm{g}$ & Salmeterol $50 \mu \mathrm{g}$ twice daily & Difference \\
\hline Total costs & $£ 7174$ & $£ 7330$ & $-£ 155$ \\
\hline Total QALYs & 3.357 & 3.339 & 0.018 \\
\hline \multirow[t]{2}{*}{ ICER } & & & Dominant $^{\mathrm{a}}$ \\
\hline & Indacaterol $300 \mu \mathrm{g}$ & Tiotropium $18 \mu \mathrm{g}$ & Difference \\
\hline Total costs & $£ 7054$ & $£ 7427$ & $-£ 374$ \\
\hline Total QALYs & 3.367 & 3.344 & 0.023 \\
\hline ICER & & & Dominant $^{\mathrm{a}}$ \\
\hline \multicolumn{4}{|c|}{ Lifetime time horizon ( 20 years) } \\
\hline & Indacaterol $150 \mu \mathrm{g}$ & Tiotropium $18 \mu \mathrm{g}$ & Difference \\
\hline Total costs & $£ 17189$ & $£ 17720$ & $-£ 532$ \\
\hline Total QALYs & 7.873 & 7.795 & 0.078 \\
\hline \multirow[t]{2}{*}{ ICER } & & & Dominant $^{\mathrm{a}}$ \\
\hline & Indacaterol $150 \mu \mathrm{g}$ & Salmeterol $50 \mu \mathrm{g}$ twice daily & Difference \\
\hline Total costs & $£ 17270$ & $£ 17485$ & $-£ 215$ \\
\hline Total QALYs & 7.866 & 7.773 & 0.093 \\
\hline \multirow[t]{2}{*}{ ICER } & & & Dominant $^{\mathrm{a}}$ \\
\hline & Indacaterol $300 \mu \mathrm{g}$ & Tiotropium $18 \mu \mathrm{g}$ & Difference \\
\hline Total costs & $£ 17,104$ & $£ 17,682$ & $-£ 579$ \\
\hline Total QALYs & 7.929 & 7.810 & 0.119 \\
\hline ICER & & & Dominant $^{\mathrm{a}}$ \\
\hline
\end{tabular}

associated with the Very Severe COPD health state. Slowing the progression to more severe COPD states also has the benefit of keeping subjects in health states with lower mortality rates. Mortality rates for all disease severity states were tested; however, indacaterol remained the dominant treatment.

The PSA shows that over $72 \%$ of iterations in the salmeterol comparison and over $89 \%$ of iterations in the tiotropium comparison appear in the south east quadrant of the cost-effectiveness plane, indicating that indacaterol was dominant in the majority of PSA iterations in both comparisons (Fig. 4). A cost-effectiveness acceptability curve (CEAC) (Fig. 5) shows the probability that an intervention is cost-effective at different thresholds for the willingness to pay for a QALY gained. At a willingness-to-pay threshold of $£ 20,000$ per QALY gain, the probability that indacaterol is cost-effective is approximately $82 \%$ and $84 \%$ for the comparisons with salmeterol and tiotropium respectively. The CEAC curve plateaus at approximately $89 \%$ for both comparisons. This is due to the small percentage of PSA iterations that resulted in inferior or dominated results (values in the northwest and southwest quadrants in Fig. 4).

The threshold analysis consisted of running the analysis for various percentage reductions on the price of tiotropium 


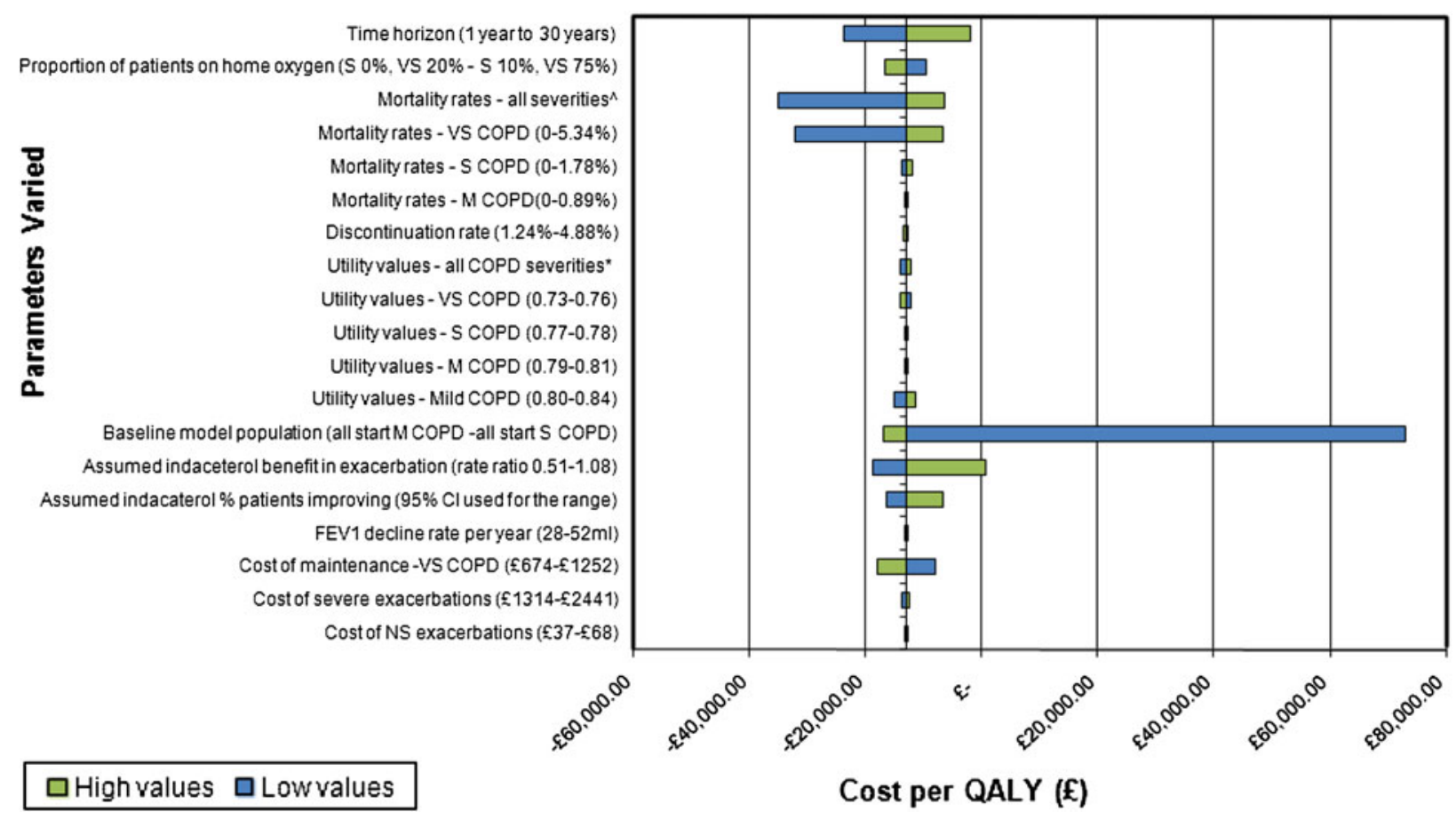

Fig. 2 Tornado diagram (indacaterol $150 \mu \mathrm{g}$ versus salmeterol $2 \times 50 \mu \mathrm{g}$ ). ${ }^{\wedge}$ Low value for the mortality rate was $0 \%$ for all severities. The high value was Moderate COPD $0.89 \%$, Severe COPD $1.78 \%$ and Very Severe COPD $5.34 \%$. *Low value for the utility was Mild COPD 0.80, Moderate COPD 0.79, Severe COPD
0.77 and Very Severe COPD 0.73 . The high value for the utility was Mild COPD 0.84, Moderate COPD 0.81, Severe COPD 0.78 and Very Severe COPD 0.76. CI confidence interval, COPD chronic obstructive pulmonary disease, $F E V 1$ forced expiratory volume in 1 second, $M$ moderate, $N S$ non-severe, $S$ severe, $V S$ very severe

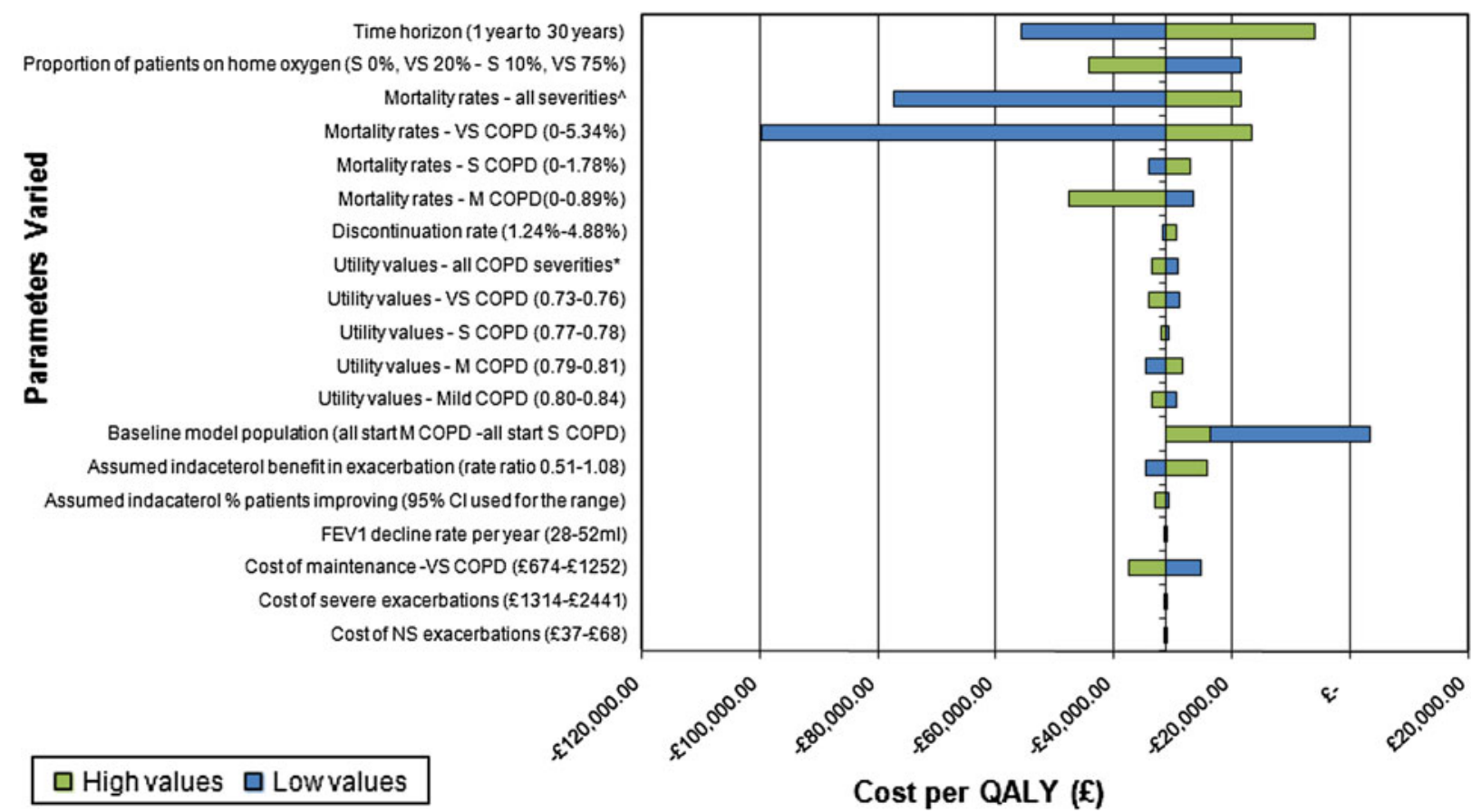

Fig. 3 Tornado diagram (indacaterol $150 \mu \mathrm{g}$ versus tiotropium $18 \mu \mathrm{g})$. ^ Low value for the mortality rate was $0 \%$ for all severities. The high value was Moderate COPD $0.89 \%$, Severe COPD $1.78 \%$ and Very Severe COPD $5.34 \%$. *Low value for the utility was Mild COPD 0.80, Moderate COPD 0.79, Severe COPD 0.77 and Very
Severe COPD 0.73. The high value for the utility was Mild COPD 0.84 , Moderate COPD 0.81, Severe COPD 0.78 and Very Severe COPD 0.76. CI confidence interval, COPD chronic obstructive pulmonary disease, FEVI forced expiratory volume in 1 second, $M$ moderate, $N S$ non-severe, $S$ severe, $V S$ very severe 


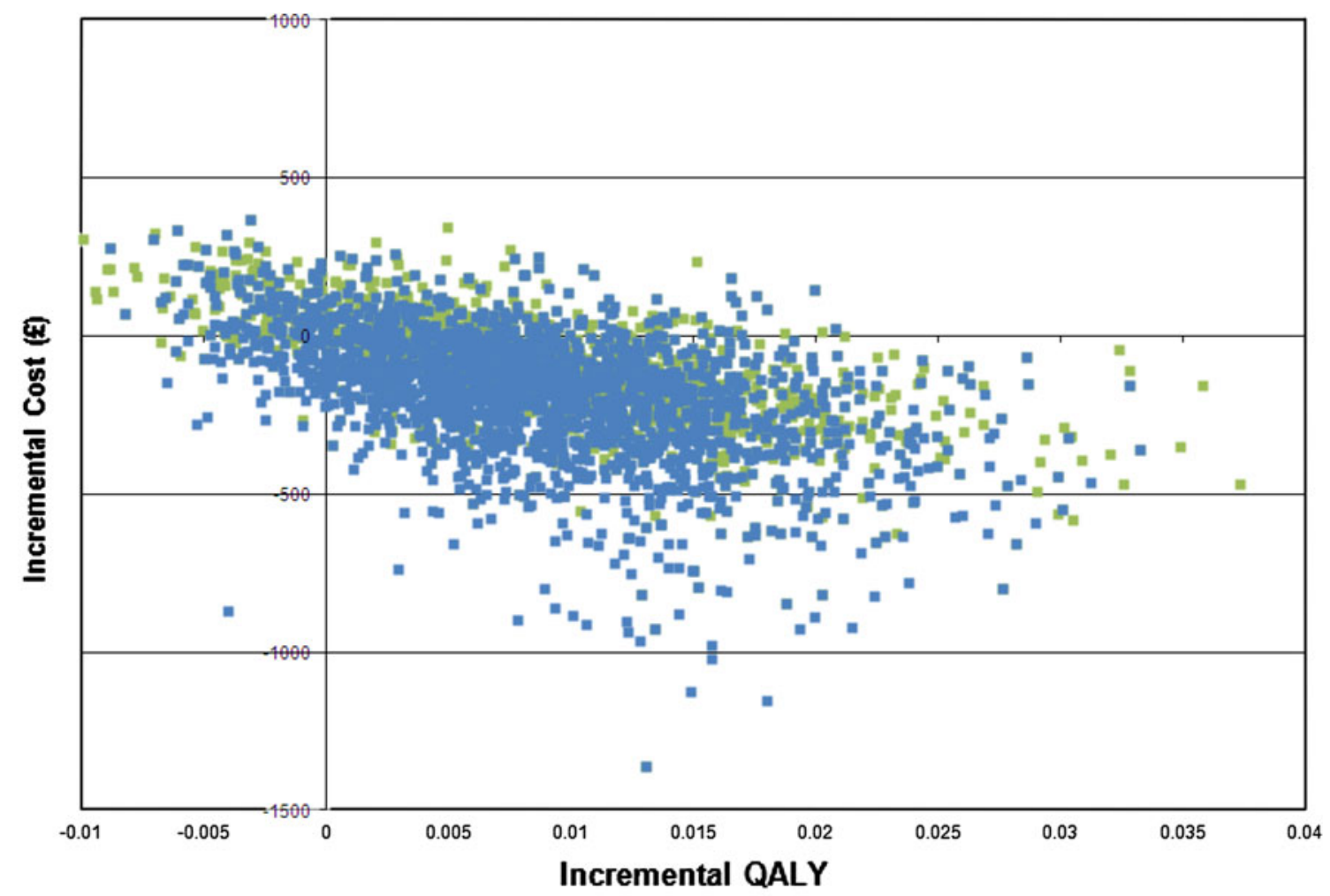

Indacaterolvs. Salmeterol $\square$ Indacaterolvs. Tiotropium

Fig. 4 Cost-effectiveness plane

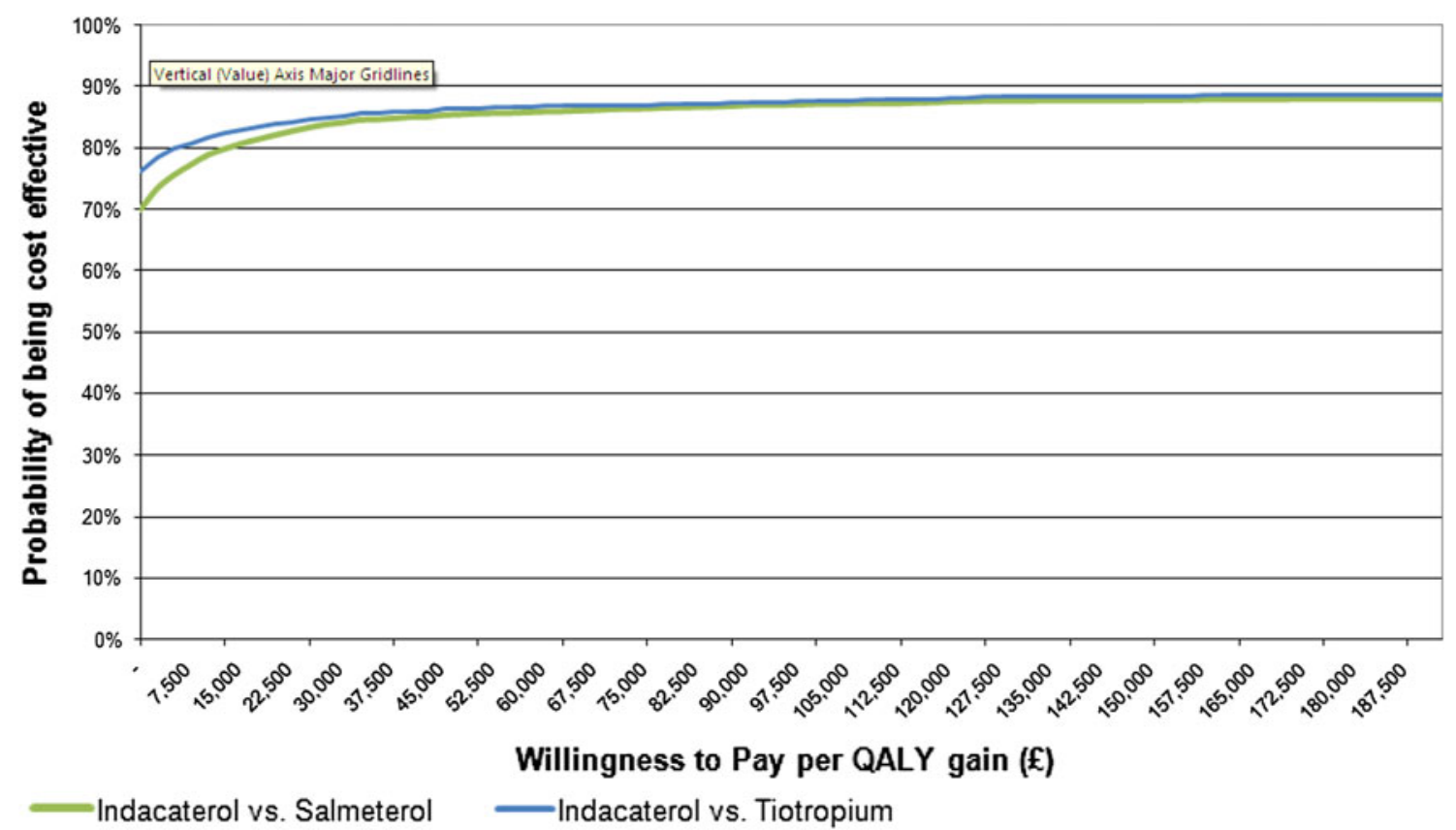

Fig. 5 Cost-effectiveness acceptability curve

after 1 year of the model time horizon. The results showed that for up to a $41 \%$ reduction on the price of branded tiotropium (a daily cost of $£ 0.63$ compared with $£ 1.06$ in the base case), indacaterol remained the dominant strategy. In over $43 \%$ of the PSA iterations, indacaterol was the dominant strategy (data not shown) and at a willingness-to- 
pay threshold of $£ 20,000$ per QALY gain, there was over $76 \%$ probability that indacaterol is cost-effective (data not shown).

\subsection{Model Validation}

The model results were compared with other studies and reviewed by an external health economist to validate its structure. Comparisons of life expectancy with several epidemiology sources for COPD patients [27, 28] as well as statistics from the US Center of Disease Control and Prevention (CDC) showed that mortality rates in the model were similar. Model inputs and outputs were also compared with existing economic evaluations [12,29] and found to be comparable.

\section{Discussion}

Clinical trials have shown that compared with both salmeterol and tiotropium, indacaterol results in greater lung volume improvements after 12 weeks of treatment [4, 5]. This clinical benefit allowed patients within the model to improve their disease severity classification in the first model cycle. This results in a larger proportion of patients in the indacaterol treatment arm initially improving to a milder disease state and therefore enjoying a better quality of life, lower costs and a slower progression to more severe states compared with those that don't benefit from the initial change to a milder disease state. This benefit was the key driver to producing ICERs which were dominant against both comparators.

The INHANCE trial included a comparison of indacaterol $300 \mu \mathrm{g}$ daily against tiotropium $18 \mu \mathrm{g}$ daily. The increased dosage of indacaterol has been shown to produce increased benefits, and can be prescribed for patients with severe COPD. In addition to the increased benefits, in the UK indacaterol $300 \mu \mathrm{g}$ daily has the same price as indacaterol $150 \mu \mathrm{g}$ daily, resulting in the increased dose also being dominant against tiotropium.

The indacaterol studies did not recruit patients on the basis of exacerbations and therefore there was a low rate of exacerbations across these trials. The trials showed a similar positive trend between all active treatments in comparison with placebo in preventing exacerbations however, the rate ratios from the trial which directly compared indacaterol with other bronchodilators all contain 1.0 in the confidence interval, thus making the results statistically non-significant. The model output for exacerbations resulted in patients in the tiotropium treatment arm having slightly more, and patients in the salmeterol arm having slightly fewer exacerbations than those in the indacaterol treatment group.
The one-way sensitivity analyses highlighted the importance of the input values for mortality rates on the results. Although no mortality benefit was assumed with any treatment, the differential mortality rates by disease severity combined with the improvement in lung function, which indirectly slowed progression to more severe COPD states which have higher mortality rates, also bestowed an indirect mortality benefit.

The composition of the model population also had a significant impact on the results. When it was assumed that the model consisted of only moderate COPD patients, the ICER increased. As a result of having a $100 \%$ moderate starting population, fewer subjects improve to a less severe disease state compared with patients starting in the severe disease state.

Another determinant of cost-effectiveness was the time horizon of the model. Extending the time horizon from 3 years to longer timeframes reduces the ICER. This is because the model assumed that the $\mathrm{FEV}_{1}$ benefit incurred at the beginning of treatment will not be lost over the course of the lifetime, that is, the slope of lines describing lung function decline will remain parallel between treatment groups until death. Other studies have shown that the initial $\mathrm{FEV}_{1}$ improvement can last up to 3 years [30] however the maintenance of benefit has not been demonstrated in longer term studies. This assumption resulted in indacaterol patients remaining in milder disease states for longer and benefiting from the indirect mortality benefit over an extended timeframe.

It is expected that when branded tiotropium loses exclusivity in the UK, the cost of tiotropium will reduce, however the extent of the price reduction is unknown. The threshold analysis showed that if the cost of tiotropium was discounted by up to $41 \%$ after 1 year of the model time horizon, indacaterol would remain the dominant strategy.

The majority of the resource utilisation data for the different health states in the model were taken from real world evidence of resource consumption by COPD patients in the UK. The use of the OPCRD [7] ensures the model reflects current clinical practice without which the results would be based on assumptions and estimations.

These results indicate that all doses of indacaterol can produce better outcomes at a lower cost to the healthcare system compared with current treatments. Although there was no clinical data to support a comparison of indacaterol $300 \mu \mathrm{g}$ with salmeterol, given that the daily cost of both indacaterol formulations are the same; the cost-effectiveness results are likely to be similar or better than the comparison with indacaterol $150 \mu \mathrm{g}$. In the context of currently available treatments for the maintenance therapy of COPD, indacaterol provided a cost-effective alternative to the current standard of care. 


\subsection{Limitations}

Limitations can arise from the model structure, model assumptions and data inputs. A limitation of Markov models is that it is not possible to record the history of a patient and therefore it cannot keep track of patients who discontinue treatment. Those who discontinue no longer benefit from the improvement in lung function from the active therapy. The trial data showed that discontinuation rates were similar among all three interventions, justifying the assumption in the model of equal discontinuation rates for all active treatments.

The key model assumption that lung function improvement changes COPD disease severity and therefore results in an implicit mortality benefit is a limitation of the model, as the clinical trials do not demonstrate this as an endpoint. However previous COPD models have set precedence for modelling lung function improvement in this way $[11,12,29]$. In addition, there is little evidence illustrating the relationship between change in lung function and change in health status [1]. In this model, improved lung function is assumed to lead to a change in health status as a result of a change in COPD disease severity.

Model inputs were taken from several sources including clinical trials, published and grey literature, and a clinical practice database. The incorporation of several sources results in the use of data derived from different and possibly inconsistent methodologies. However the impact on the ICER results were minimised by using a consistent source for the equivalent model input across all treatments arms.

There were some limitations with the use of the OPCRD database [7]. The OPCRD only captures medical data recorded in GP practices. Therefore any resource use prescribed by specialists was incompletely recorded. Since the more severe COPD patients are more likely to be treated by a specialist, the cost of managing the more severe health states may be underestimated.

As with most RCTs, patients with unstable co-morbidities were excluded from the study. Therefore the generalisability of these results is limited to the patient population of the indacaterol clinical trials. There is some evidence that patients with COPD also suffer from several co-morbidities and patients with more severe COPD may also have more numerous and severe co-morbid conditions $[1,31]$. Although this is not reflective of real world evidence, the inclusion/exclusion criteria applied equally to all treatment arms and therefore should not bias the ICER. However a greater understanding of the impact of comorbidities in the COPD population may lead to a more accurate estimate.

The clinical data used in this model were derived from trials of 6-month duration and therefore a limitation of the analysis is the uncertainty introduced in extrapolating these data to the 3-year base-case period and the longer time horizons assessed. Real world evidence or analyses based on trials with a longer duration are recommended to validate the model's longer-term projections in the future.

Clinical studies of 6-month durations may also not sufficiently capture seasonal variation with regard to exacerbation rates and therefore a model based on these may not be generalisable to real-world exacerbation rates. However recruitment in the studies was spread out such that the total observation period spanned more than 6 months and was conducted in both the northern and southern hemispheres.

These studies also had a very low overall rate of exacerbations observed and are not the ideal data source for exacerbations, but are the best data to describe the exacerbation benefits of indacaterol currently available. More clinical trial data addressing the exacerbation benefit is expected to be reported later in 2013. To test the uncertainty of the clinical evidence, these parameters are included in the one-way and probabilistic sensitivity analyses. Given the very low and very similar rates of exacerbation between the comparators, disabling the exacerbation parameters had very little impact on the results.

\section{Conclusion}

The current cost-utility analysis combined real-world evidence with clinical trial data to compare indacaterol with tiotropium and salmeterol for use as maintenance treatment for COPD in the UK. The analysis demonstrated that indacaterol dominates in both comparisons and is likely to remain cost-effective under a range of assumptions. The comparison of indacaterol $300 \mu \mathrm{g}$ with tiotropium shows that the higher-dose form is still well positioned to demonstrate cost-effectiveness. As a potential first-line maintenance treatment for moderate and severe COPD patients, indacaterol is a cost-effective alternative to current standard of care.

\section{Acknowledgments}

Funding Funding for the conduct of the study and the preparation of this paper was provided by Novartis Pharmaceuticals, UK Limited. The funding organisation (Novartis Pharmaceuticals UK Limited) was involved in the review and approval of the design, analysis and interpretation of data. They were also involved in the review and approval of the manuscript.

Conflicts of interest David Price has received honoraria from Novartis Pharmaceuticals UK Limited.

Yumi Asukai and Jaithri Ananthapavan are employees of IMS Health which has received consultancy fees from Novartis Pharmaceuticals UK Limited. 
Bill Malcolm, Amr Radwan and Ian Keyzor are employees of Novartis Pharmaceuticals UK Limited.

Author contributions David Price was involved in original study concept, design of the study, development of the real life data included, interpretation and writing of the publication. He is the guarantor of the content of this paper.

Yumi Asukai was responsible for the development of the original cost-effectiveness model used for this adaptation and was involved in the preparation and critical review of the manuscript.

Jaithri Ananthapavan undertook the model adaptation to the UK setting, completed the analyses and made a significant contribution to the writing of the manuscript.

Bill Malcolm originally conceived the concept and idea for adapting this Markov model to the UK market in response to the need for local UK payers. He has been responsible for checking the accuracy of all iterations of the manuscript.

Amr Radwan contributed to the medical content of the publication, and to the reviews of iterations of the manuscript and its final approval.

Ian Keyzor was part of the core team during the initial manuscript kick-off discussions and also reviewed various manuscript drafts and provided suggested revisions when necessary.

Open Access This article is distributed under the terms of the Creative Commons Attribution Noncommercial License which permits any noncommercial use, distribution, and reproduction in any medium, provided the original author(s) and the source are credited.

\section{References}

1. Global Initiative for Chronic Obstructive Lung Disease. Global strategy for the diagnosis, management, and prevention of chronic obstructive pulmonary disease (revised 2011) (online). http://www.goldcopd.org/uploads/users/files/GOLD_Report_2011_ Jan21.pdf. Accessed 23 Jan 2012.

2. National Institute for Health and Clinical Excellence. Chronic obstructive pulmonary disease management of chronic obstructive pulmonary disease in adults in primary and secondary care (partial update). This guideline partially updates and replaces NICE clinical guideline 12 (online). http://guidance.nice.org.uk/CG101/NICE Guidance/pdf/English. Accessed 23 Jan 2012.

3. Department of Health /Medical Directorate/Respiratory Team. Consultation on a strategy for services for chronic obstructive pulmonary disease (COPD) in England (online). http://www.pcrsuk.org/copd_qrg/qrg_strategy_in_full.pdf. Accessed 2 Feb 2012.

4. Donohue JF, Fogarty C, Lotvall J, et al. Once-daily bronchodilators for chronic obstructive pulmonary disease: indacaterol versus tiotropium. Am J Respir Crit Care Med. 2010;182(2):155-62.

5. Kornmann O, Dahl R, Centanni S, et al. Once-daily indacaterol versus twice-daily salmeterol for COPD: a placebo-controlled comparison. Eur Respir J. 2011;37(2):273-9.

6. Vogelmeier C, Ramos-Barbon D, Jack D, et al. Indacaterol provides 24-hour bronchodilation in COPD: a placebo-controlled blinded comparison with tiotropium. Respir Res. 2010;11(1):135.

7. Optimum Patient Care. The optimum patient care research database. 2012 (data on file).

8. Price D, Gray A, Gale R, Asukai Y, Mungapen L, Lloyd A, et al. Cost-utility analysis of indacaterol in Germany: a once-daily maintenance bronchodilator for patients with COPD. Respir Med. 2011;105(11):1635-47.

9. National Institute for Health and Clinical Excellence. Guide to the methods of technology appraisal (online). http://www.nice.org.uk/
media/B52/A7/TAMethodsGuideUpdatedJune2008.pdf Accessed 20 Jan 2012.

10. Oostenbrink JB, Rutten-van Molken MP, Al MJ, et al. One-year cost-effectiveness of tiotropium versus ipratropium to treat chronic obstructive pulmonary disease. Eur Respir J. 2004;23(2):241-9.

11. Oostenbrink JB, Rutten-van Molken MPH, Monz BU, et al. Probabilistic Markov model to assess the cost-effectiveness of bronchodilator therapy in COPD patients in different countries. Value Health. 2005;8(1):32-46.

12. Rutten-van Molken MP, Oostenbrink JB, Miravitlles M, et al Modelling the 5-year cost effectiveness of tiotropium, salmeterol and ipratropium for the treatment of chronic obstructive pulmonary disease in Spain. Eur J Health Econ. 2007;8(2): 123-35.

13. Sin DD, Golmohammadi K, Jacobs P. Cost-effectiveness of inhaled corticosteroids for chronic obstructive pulmonary disease according to disease severity. Am J Med. 2004;116(5):325-31.

14. Penning-van Beest F, van Herk-Sukel M, Gale R, et al. Threeyear dispensing patterns with long-acting inhaled drugs in COPD: a database analysis. Respir Med. 2011;105(2):259-65.

15. Rutten-van Molken M, Lee TA. Economic modelling in chronic obstructive pulmonary disease. Proc Am Thorac Soc. 2007;3:630-4.

16. Tashkin DP, Celli B, Senn S, et al. A 4-year trial of tiotropium in chronic obstructive pulmonary disease. N Engl J Med. 2008; 359(15):1543-54.

17. Office of National Statistics. United Kingdom, Interim Life Tables, 1980-82 to 2008-10 (online). http://www.ons.gov.uk/ ons/publications/re-reference-tables.html?edition=tcm\%3A77223324. Accessed 16 Jan 2012.

18. Curtis L. Unit Costs of Health and Social Care 2011. Personal Social Services Research Unit, The University of Kent. 2011 (online). http://www.pssru.ac.uk/pdf/uc/uc2011/uc2011.pdf. Accessed 16 Jan 2012.

19. Department of Health. NHS reference costs 2009-2010 (online). http://www.dh.gov.uk/en/Publicationsandstatistics/Publications/ PublicationsPolicyAndGuidance/DH_123459. Accessed 16 Jan 2012.

20. British National Formulary (BNF) 62 (online). 2011. http://bnf. org/bnf/bnf/current/login.htm?uri=http $\% 3 \mathrm{~A} \% 2 \mathrm{~F} \% 2 \mathrm{Fbnf}$.org\% 2Fbnf\%2Fbnf\%2F57\%2F104945.htm. Accessed 16 Jan 2012.

21. The NHS Information Centre. Prescription Cost Analysis, England. 2010 (online). http://www.ic.nhs.uk/statistics-and-datacollections/primary-care/prescriptions/prescription-cost-analysisengland-2010. Accessed 12 Jan 2012.

22. NHS. Home Oxygen Service. 2012. http://www.homeoxygen. nhs.uk/1.php. Accessed 2 Feb 2012.

23. EuroQol Group. What is EQ-5D. 2012. http://www.euroqol. org/eq-5d/what-is-eq-5d.html. Accessed 2 Feb 2012.

24. Asukai Y, Baldwin M, Mungapen L. Utility values for COPD patients based on the EQ-5D questionnaire from three indacaterol Phase III studies [abstract P84]. Thorax. 2012;67 Suppl 2:A1-193 (Poster presented at British Thoracic Society Winter Meeting, London; 5-7 December 2012).

25. Kind P, Dolan P, Gudex C, et al. Variations in population health status: results from a United Kingdom national questionnaire survey. BMJ. 1998;316(7133):736-41.

26. Rutten-van Mölken MP, Hoogendoorn M, Lamers L. Holistic preferences for 1-year health profiles describing fluctuations in health: the case of chronic obstructive pulmonary disease. Pharmacoeconomics. 2009;27(6):465-77.

27. Hart CL, Smith GD, Hole DJ, et al. Carboxyhaemoglobin concentration, smoking habit, and mortality in 25 years in the Renfrew/Paisley prospective cohort study. Heart. 2006;92(3):321-4.

28. Menotti A, Blackburn H, Seccareccia F, et al. The relation of chronic diseases to all-cause mortality risk-the Seven Countries Study. Ann Med. 1997;29(2):135-41. 
29. Spencer M, Briggs AH, Grossman RF, et al. Development of an economic model to assess the cost effectiveness of treatment interventions for chronic obstructive pulmonary disease. Pharmacoeconomics. 2005;23(6):619-37.

30. Calverley PM, Anderson JA, Celli B, et al. Salmeterol and fluticasone propionate and survival in chronic obstructive pulmonary disease. N Engl J Med. 2007;356(8):775-89.
31. Curkendall SM, Lanes S, de Luise C, et al. Chronic obstructive pulmonary disease severity and cardiovascular outcomes. Eur J Epidemiol. 2006;21(11):803-13.

32. Department of Health (DH) and Health Protection Agency (HPA). Seasonal Flu Vaccine Uptake. https://www.wp.dh.gov.uk/ winterwatch/files/2012/01/Seasonal-flu-GP-patients-Sept-to-Dec2011.pdf. Accessed 2 Feb 2012. 